\title{
Application of Catalytic Hydrogen Evolution in the Presence of Neonicotinoid Insecticide Clothianidin
}

\author{
Dariusz Guziejewski • Slawomira Skrzypek • \\ Witold Ciesielski
}

Received: 22 March 2011 / Accepted: 16 May 2011 / Published online: 31 May 2011

(C) The Author(s) 2011. This article is published with open access at Springerlink.com

\begin{abstract}
Clothianidin, a new generation of pesticide, was determined in spiked tap water, apple juice, and soil by square-wave adsorptive stripping voltammetry. The method of determination is based on the hydrogen evolution reaction catalyzed by clothianidin at the hanging mercury drop electrode. The optimal signal was detected at $-1.4 \mathrm{~V}$ versus $\mathrm{Ag} / \mathrm{AgCl}$ in citrate buffer at $\mathrm{pH}$ 2.2. Various parameters such as $\mathrm{pH}$, buffer concentration, frequency, amplitude, step potential, accumulation time, and potential were investigated to enhance the sensitivity of the determination. The optimal results were recorded at an accumulation potential of $-0.35 \mathrm{~V}$, accumulation time of $7 \mathrm{~s}$, amplitude of $100 \mathrm{mV}$, frequency of $200 \mathrm{~Hz}$, and step potential of $7 \mathrm{mV}$. The mechanism of catalytic hydrogen evolution was considered under experimental and theoretical conditions. This electroanalytical procedure enabled to determine clothianidin in the concentration range $9 \times 10^{-9}-4 \times 10^{-6} \mathrm{~mol} \mathrm{~L}^{-1}$ in supporting electrolyte and tap water, $1 \times 10^{-7}-4 \times 10^{-6} \mathrm{~mol} \mathrm{~L}^{-1}$ in diluted apple juice, and $2 \times 10^{-7}-1 \times 10^{-6} \mathrm{~mol} \mathrm{~L}^{-1}$ in soil. The detection and quantification limits in supporting electrolyte and diluted apple juice were found to be $2.6 \times 10^{-9}, 8.6 \times 10^{-9}$ and $3 \times 10^{-8}$, and $1 \times 10^{-7} \mathrm{~mol} \mathrm{~L}^{-1}$, respectively. A standard addition method was successfully used to determine clothianidin in spiked tap water, spiked apple juice, and spiked soil.
\end{abstract}

D. Guziejewski · S. Skrzypek $(\bowtie) \cdot$ W. Ciesielski

Department of Instrumental Analysis, University of Lodz, Pomorska 163,

90-236 Lodz, Poland

e-mail: skrzypek@uni.lodz.pl

D. Guziejewski

e-mail: dguziejewski@uni.lodz.pl

W. Ciesielski

e-mail: ciesielski@uni.lodz.pl
Keywords Clothianidin · Voltammetry · Catalytic hydrogen evolution · Determination · Guanidine group

\section{Introduction}

Clothianidin ((E)-1-(2-chloro-1,3-thiazol-5-ylmethyl)-3methyl-2-nitroguanidine, CLT) is a new pesticide belonging to the group of neonicotinoid insecticides. Such pesticides are antagonists against nicotinic acetylcholine receptor. The structural features of CLT are an open-chain nitroguanidine skeleton and a thiazole ring (inset in Fig. 1). As its biological advantages, potent activity against Diptera, Coleoptera, and Lepidoptera pests in addition to Hemiptera and Thysanoptera, long-term control effect, excellent systemic action, and a wide variety of treatment methods can be pointed out (Uneme 2011). Neonicotinoids are the most important chemical class of insecticides introduced to the global market since synthetic pyrethroids. These pesticides are registered globally in more than 120 countries, and they are among the most effective insecticides to control a broad spectrum of sucking and certain chewing pests (Jeschke et al. 2011). The important drawback of CLT is that it can be toxic for useful insects $\left(\mathrm{LD}_{50}=0.0038 \mu \mathrm{g}\right.$ per bee; Schmuck and Keppler 2003). The discovery of neonicotinoid insecticides can be considered as a milestone in agrochemical research over the past three decades. Today, the neonicotinoids represent the fastest-growing class of insecticides introduced onto the market. In 2006, the neonicotinoid family accounted for worldwide annual sales of around US $\$ 1.56$ billion, representing nearly $17 \%$ of the global insecticide market (Jeschke and Nauen 2008).

Residues of pesticides found in agricultural products, drinking water, and environmental exposure have been a 


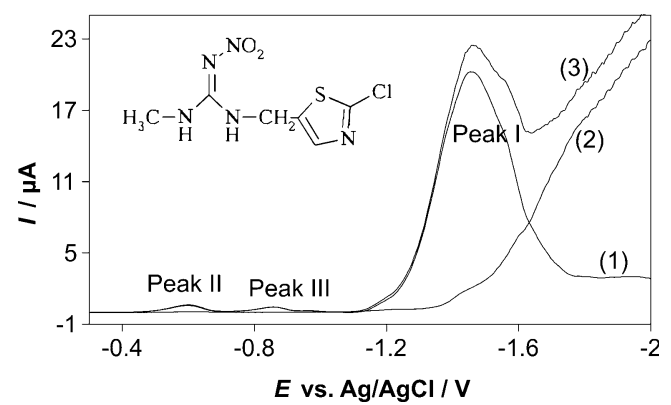

Fig. $1 \mathrm{SW}$ voltammogram of $2 \times 10^{-6} \mathrm{~mol} \mathrm{~L}^{-1}$ CLT recorded in citrate buffer at $\mathrm{pH} 2.2$, accumulation $30 \mathrm{~s}$ at $-0.3 \mathrm{~V}$. Components of the voltammetric response: 1 net, 2 backward, and 3 forward current. The parameters of the potential modulation were frequency $f=200 \mathrm{~Hz}$, amplitude $E_{\mathrm{sw}}=100 \mathrm{mV}$, and step potential $\Delta E=5 \mathrm{mV}$. Inset chemical structure of clothianidin

great concern in recent years (Sreedhar et al. 2010). The existence of such compounds in dietary products or environment is a threat to human life, and its determination at trace levels is an acute analytical problem. Among various determination methods of pesticides, i.e., chromatographic or spectrophotometric, those based on voltammetry have its own significant contribution (Mirceski et al. 2010; Thriveni et al. 2009; Pacheco et al. 2010). Although the use of voltammetric techniques has been often exploited in determination of neonicotinoid pesticides, to our knowledge, only one paper is available regarding CLT and the use of modified carbon paste electrode (Papp et al. 2009).

In our previous work, we reported on the determination of CLT with square-wave voltammetry (SWV) on a hanging mercury drop electrode (HMDE; Guziejewski et al. 2011). This analysis was based on the reduction of the nitro group present in the pesticide structure. Recently, our attention focused on the application of catalytic hydrogen evolution (CHE) in the presence of compounds with guanidine group in their structure to their determination in various matrices (Mirceski et al. 2005; Skrzypek et al. 2009; Skrzypek 2010). As a continuation of our previous study, the aim of the present work was to investigate the voltammetric behavior of CLT based on the catalytic hydrogen evolution in the presence of guanidine group included in the pesticide structure and to elaborate a rapid, simple, and sufficiently sensitive electrochemical method for the determination of this compound in tap water, apple juice, and soil samples.

\section{Materials and Methods}

Instrumentation

All experiments were performed at microAutolab/GPES (General Purpose Electrochemical System Version 4.9, Eco Chemie, the Netherlands) computer-controlled electrochemi- cal system. A controlled growth mercury drop electrode (MTM Anko Instruments, Poland) was used as a working electrode (electrode area $0.0102 \mathrm{~cm}^{2}$ ). All potentials were referred to the $\mathrm{Ag} / \mathrm{AgCl}\left(3 \mathrm{~mol} \mathrm{~L}^{-1} \mathrm{KCl}\right)$ reference electrode, whereas the counter electrode was a platinum wire. $\mathrm{A} \mathrm{pH}$ meter (type CP-315, Elmetron, Poland) with a conjugated glass membrane electrode was also used.

\section{Reagents}

Clothianidin (99.5\%) and other pesticides (methidathion, diazinon, acibenzolar- $S$-methyl, demeton, cyromazine, thiophanate methyl, and fenthion) were purchased from Dr. Ehrenstorfer (Germany). Acetone for HPLC and acetic acid (99.5\%) were purchased from Labscan (Poland) and Merck (Germany), respectively. Sodium hydroxide, ethanol, and acids: phosphoric $(85 \%)$, boric, hydrochloric, and citric were of analytical grade and purchased from POCh (Poland). Argon $(5 \mathrm{~N})$ was from Linde Gas (Poland), and it was used without further purification. Britton-Robinson or citrate buffers were used as the supporting electrolyte. Their concentration was 0.04 and $0.1 \mathrm{~mol} \mathrm{~L}^{-1}$, respectively. Triply distilled and deionized water was used throughout the experiments.

\section{General Voltammetric Procedure}

The general procedure used to obtain cathodic stripping voltammograms was as follows: $10 \mathrm{ml}$ of the supporting electrolyte ( $7 \mathrm{ml}$ of the buffer mixed with $3 \mathrm{ml}$ of the water) was placed in the voltammetric cell, and the solution was purged with argon for $600 \mathrm{~s}$ with stirring. After forming a new drop, the accumulation step at a constant potential was applied with stirring of the solution, followed by a resting period of $5 \mathrm{~s}$. Following the equilibrium step, a negative ongoing potential scan was applied. If some reagents were subsequently added, the solution was purged with argon for further $30 \mathrm{~s}$. The reported signals were measured after subtracting of the blank solution. In the present study, the optimal results were obtained in citrate buffer at $\mathrm{pH} 2.2$, an accumulation potential of $-0.35 \mathrm{~V}$, amplitude of $100 \mathrm{mV}$, frequency of $200 \mathrm{~Hz}$, and step potential of $7 \mathrm{mV}$. Accumulation time of $7 \mathrm{~s}$ was selected. All measurements were performed at room temperature.

Preparation of Solutions and Sample Treatment

A stock solution of CLT $\left(1 \times 10^{-3} \mathrm{~mol} \mathrm{~L}^{-1}\right)$ was prepared by dissolving the adequate amount of the pesticide in a mixture of water and acetone $(4: 1, v / v)$. All dilute solutions were prepared from the stock solution.

Tap water, apple juice, and soil samples were used as test samples. Packed grape juice was purchased from the local market; tap water and soil samples were collected from the local water supplier and nearby fields, respectively. 
These samples were spiked with the analyte without any pretreatment except proper dilution.

Analysis of Clothianidin in Samples

\section{Tap Water}

To investigate possible interference with tap water, $3 \mathrm{~mL}$ of the sample was added to a voltammetric cell containing $7 \mathrm{~mL}$ of citrate buffer at $\mathrm{pH} 2.2$. When the initial blank signal was recorded, the required volumes of CLT were added by means of a micropipette in the concentration range from $2 \times 10^{-8}$ to $2 \times 10^{-7} \mathrm{~mol} \mathrm{~L}^{-1}$.

\section{Apple Juice}

One milliliter of juice was placed in a $100-\mathrm{mL}$ calibrated flask and filled up to the mark with water. Next $50 \mu \mathrm{L}$ of the diluted apple juice was transferred to the voltammetric cell containing $7 \mathrm{~mL}$ of citrate buffer ( $\mathrm{pH} 2.2)$ and $3 \mathrm{~mL}$ of water. When the initial blank signal was recorded, the required volumes of CLT were added by means of a micropipette in the concentration range from $1 \times 10^{-7}$ to $4 \times 10^{-6} \mathrm{~mol} \mathrm{~L}^{-1}$.

\section{Soil}

A mass of $2.0 \mathrm{~g}$ of soil sample was vigorously mixed with $2 \mathrm{~mL}$ of ethanol and $8 \mathrm{~mL}$ of citrate buffer at $\mathrm{pH} 2.2$. This mixture was then centrifuged for $3 \mathrm{~min}$ at 10,000 rpm and transferred to a $50-\mathrm{mL}$ volumetric flask, and the volume was completed with pure water. The aliquots of $40 \mu \mathrm{L}$ of this solution with $7 \mathrm{~mL}$ of citrate buffer and $3 \mathrm{~mL}$ of water were mixed in the voltammetric cell. When the initial blank signal was recorded, the required volumes of CLT were added by means of a micropipette in the concentration range from $2 \times 10^{-7}$ to $1 \times 10^{-6} \mathrm{~mol} \mathrm{~L}^{-1}$.

Voltammograms of the samples were recorded at the same parameters as for pure pesticide analysis. The recovery of the drug was calculated in sextuplicate experiments.

Analysis of Clothianidin in Spiked Samples

\section{Tap Water}

CLT stock solution $(3.3 \mu \mathrm{L})$ was placed in a $50-\mathrm{mL}$ calibrated flask and filled up to the mark with tap water. Next $3 \mathrm{~mL}$ of the spiked water was transferred to the voltammetric cell containing $7 \mathrm{~mL}$ of citrate buffer ( $\mathrm{pH} 2.2$ ). The concentration of the pesticide in the voltammetric cell was $2 \times 10^{-8} \mathrm{~mol} \mathrm{~L}^{-1}$. Analogously to the previous description, $33.3 \mu \mathrm{L}$ of CLT stock solution was taken in order to achieve final concentration $2 \times 10^{-7} \mathrm{~mol} \mathrm{~L}^{-1}$.

\section{Apple Juice}

Diluted spiked apple juice was fortified with proper amount of CLT, and $50 \mu \mathrm{L}$ of such solution was transferred to the voltammetric cell containing $7 \mathrm{~mL}$ of citrate buffer at $\mathrm{pH} 2.2$ and $3 \mathrm{~mL}$ of water. The concentration of the pesticide in the voltammetric cell was $2 \times 10^{-7} \mathrm{~mol} \mathrm{~L}^{-1}$.

\section{Soil}

A mass of $2.0 \mathrm{~g}$ of soil was vigorously mixed with $0.5 \mathrm{~mL}$ of CLT stock solution, $2 \mathrm{~mL}$ of ethanol, and $8 \mathrm{~mL}$ of citrate buffer at $\mathrm{pH}$ 2.2. This mixture was then centrifuged for $3 \mathrm{~min}$ at $10,000 \mathrm{rpm}$, transferred to a $50-\mathrm{mL}$ volumetric flask, and filled up to the mark with deionized water. Forty microliters of this solution, $7 \mathrm{~mL}$ of citrate buffer, and $3 \mathrm{~mL}$ of water were transferred to the voltammetric cell. The concentration of the pesticide in the voltammetric cell was $2 \times 10^{-7} \mathrm{~mol} \mathrm{~L}^{-1}$.

The voltammograms of spiked samples were recorded at the same parameters as for raw sample material. The recovery of the drug was calculated in six runs. Quantifications were performed by means of the standard addition method.

\section{Results and Discussion}

Selection of Experimental and Instrumental Conditions

In order to achieve optimal experimental and instrumental conditions for the determination of clothianidin (its chemical structure is depicted in inset to Fig. 1) using HMDE, extensive studies were performed. The first critical choice was the supporting electrolyte. BrittonRobinson (BR) buffer (pH 1.7 to 9.5) and citrate buffer (pH 1.5 to 3.8) were chosen as the supporting electrolytes. The highest analytical signals of CLT (with respect to peak I) were observed in acidic medium of BR buffer, with the slightly higher sensitivity and better peak shapes achieved in citrate buffer $\mathrm{pH} 2.2$ (Fig. 1). The peak height decreased substantially with increasing $\mathrm{pH}$ indicating involvement of the proton in the reaction mechanism. The stability of the CLT voltammetric response was observed over 5 days. The voltammetric response from that pesticide in this buffer consists of three signals, peak I at about $-1.4 \mathrm{~V}$ and peaks II and III at -0.6 and $-0.85 \mathrm{~V}$, respectively. The latter two resulted from a two-step irreversible reduction of nitro group into amine group; their analytical applicability was elaborated in our previous studies (Guziejewski et al. 2011). We believe that the peak I is attributed to catalytic hydrogen evolution induced by the presence of a guanidine group in the CLT structure as a result of a 
decreased hydrogen overvoltage. Among various catalytic electrode mechanisms, those based on the hydrogen evolution reaction are the most sensitive ones (Banica and Ion 2000). Catalytic current is well-known in the literature for their high analytical usefulness. Also catalytic electrode reaction based on hydrogen evolution has been proven to be of particular analytical utility for determination of compounds of pharmacological relevance (Smyth and Vos 1992).

Observed CLT response is highly sensitive to the accumulation factor. The influence of the accumulation potential $\left(E_{\text {dep }}\right)$ was studied in the potential range from 0.3 to $-0.5 \mathrm{~V}$ and $10 \mathrm{~s}$ accumulation time $\left(t_{\mathrm{dep}}\right)$. As $E_{\mathrm{dep}}$ decreased, an increase of CLT signal was observed with the maximum between -0.4 and $-0.3 \mathrm{~V}$. Further decrease of $E_{\text {dep }}$ values causes a decrease in response as the values approached $-0.5 \mathrm{~V}$. Accumulation potential $-0.35 \mathrm{~V}$ was used in consecutive studies. The CLT signal increased as accumulation time was introduced. Maximum response was achieved with $t_{\text {dep }} 7 \mathrm{~s}$. Further increase of accumulation time caused a significant decrease in the voltammetric response of the pesticide. Such behavior suggests high affinity of CLT molecules to the electrode surface.

The influence of the amplitude $E_{\mathrm{sw}}$ was studied in the range from 10 to $200 \mathrm{mV}$. The CLT peak was studied with respect to its height $I_{\mathrm{p}}$ as well as its half peak width $\Delta E_{\mathrm{p} / 2}$. $I_{\mathrm{p}}$ increased as the amplitude value approached $100 \mathrm{mV}$ and remained constant up to $200 \mathrm{mV}$. $\Delta E_{\mathrm{p} / 2}$ remained constant up to $E_{\mathrm{sw}}=100 \mathrm{mV}$ and after that started to increase proportionally with amplitude. Analysis of the ratio $I_{\mathrm{p}} / \Delta E_{\mathrm{p} / 2}$ showed maximum for an amplitude $100 \mathrm{mV}$, and this value was used in further studies. Analysis of backward component of the SW response showed it had the same sign as forward component. Its contribution to the overall net response decreases substantially as the value of amplitude approach $100 \mathrm{mV}$ and remained constant at higher values of $E_{\mathrm{sw}}$.

The influence of a scan rate applied to the working electrode potential in square-wave voltammetry can be studied by the alteration of step height and frequency. The highest response was observed with a step height $7 \mathrm{mV}$. Further increase of the parameter value caused a decrease in the response and ill shape of the CLT peak. The influence of the frequency is presented in Fig. 2 where consequent increase in the CLT voltammetric response is observed. In the consecutive studies $200 \mathrm{~Hz}$ value was used, as at this frequency, the CLT gave a high response current and a well-defined peak shape (with respect to $\Delta E_{\mathrm{p} / 2}$ and the ratio $\left.I_{\mathrm{p}} / \Delta E_{\mathrm{p} / 2}\right)$. Although the use of a higher frequency would give a slightly higher response, we decided to avoid these because of uncompensated ohmic drop effect (Mirceski and Lovric 2001) which cannot be disregarded at very fast potential scanning. $f / \mathrm{Hz}$

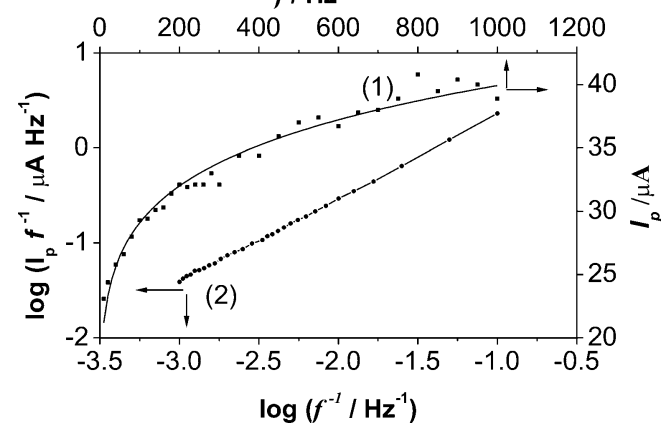

Fig. 2 Effect of the SW frequency on the $2 \times 10^{-6} \mathrm{~mol} \mathrm{~L}^{-1}$ CLT peak current (curve 1, right and upper ordinate). Logarithmic dependence of the ratio $I / f$ on the inverse of the SW frequency, $f$ (curve 2, left and bottom ordinate). Supporting electrolyte as in Fig. 1. The parameters of the potential modulation were: amplitude $E_{\mathrm{sw}}=100 \mathrm{mV}$ and step potential $\Delta E=7 \mathrm{mV}$; accumulation for $3 \mathrm{~s}$ at $-0.35 \mathrm{~V}$

Hence, a scan rate of $1,400 \mathrm{mV} \mathrm{s}^{-1}$ was established for further studies.

Cyclic voltammogram of CLT showed only one peak (at $-1.4 \mathrm{~V}$ ) in the cathodic run close to the hydrogen evolution of the supporting electrolyte. Since no anodic peak was observed during the reverse scan, it suggests an irreversible behavior of the voltammetric response. No signals related to the reduction of nitro group were observed at this concentration of pesticide.

\section{Mechanism Studies}

Theoretical and experimental studies on the catalytic hydrogen evolution reaction in the presence of an adsorbed catalyst by means of square-wave voltammetry have been recently performed (Mirceski et al. 2005). The electrode mechanism involves preceding chemical reaction, in which the adsorbed catalyst (Cat) is undergoing protonation (Eq. 1), and the protonated form of the catalyst is irreversibly reduced yielding the initial form of the catalyst and atomic hydrogen (Eq. 2):

$\mathrm{Cat}(\mathrm{ads})+\mathrm{H}_{(\mathrm{aq})}^{+} \stackrel{k_{\mathrm{p}}^{\prime}}{\stackrel{k_{\mathrm{d}}}{\longrightarrow}} \mathrm{CatH}^{+}(\mathrm{ads})$

$\mathrm{CatH}^{+}($ads $)+\mathrm{e}^{-} \rightarrow \mathrm{Cat}(\mathrm{ads})+\mathrm{H}_{(\mathrm{aq})}$

$k_{\mathrm{p}}^{\prime}\left(\mathrm{mol}^{-1} \mathrm{~L} \mathrm{~s}^{-1}\right)$ and $k_{\mathrm{d}}\left(\mathrm{s}^{-1}\right)$ are rate constants of the protonation and dissociation reactions, respectively. The resulting equilibrium constant of that reaction will be $K=$ $k_{\mathrm{p}}^{\prime} / k_{\mathrm{d}}\left(\mathrm{mol}^{-1} \mathrm{~L}\right)$, whereas the electrode reaction (Eq. 2) is characterized with the surface standard rate constant $k_{\mathrm{S}}$ and the electron transfer coefficient $\alpha$. As the experiment is performed in a buffered solution, the concentration of $\mathrm{H}^{+}$ at the electrode surface is constant on the time scale of the experiment. Hence, the protonation reaction can be 
associated with a pseudo-first order rate constant defined as $k_{\mathrm{p}}=k_{\mathrm{p}}^{\prime} c\left(\mathrm{H}^{+}\right)$. CLT plays the role of a catalyst as compounds with guanidine moiety in the structure can easily adsorb at the mercury surface and undergo protonation (Skrzypek et al. 2009).

First description and theoretical studies of CHE in the case of guanidine compounds and SWV have been elaborated for famotidine (Mirceski et al. 2005). Here, we will only briefly describe the most important features of such mechanism and confirm the proposed mechanism of catalytic hydrogen evolution in the presence of guanidine compound-clothianidin. The voltammetric response of any surface process can be generalized as $I=n F f A \Gamma^{*} \Psi$, where $n$ is the number of electrons, $F$ is Faraday constant, $A$ is the electrode surface area, $\Gamma^{*}$ is the surface concentration of the electroactive reactant, $f$ is the SW frequency, and $\Psi$ is the dimensionless function typical for particular electrode reaction. The product $n F f A \Gamma^{*}$ can be understood as a constant, whereas all information regarding the electrode mechanism and kinetics are given in the dimensionless function $\Psi$ which is a complex function. Its properties depend on the kinetic parameters, mass transfer parameters, as well as the frequency of the potential modulation. From the above definition of the current measured in SWV, it follows that the ratio $I / f$, i.e., the ratio of the real current measured at particular frequency, is proportional to the dimensionless function $\Psi$. Hence, in a mechanistic study, one compares the ratio $I / f$ with the properties of the function $\Psi$.

The recurrent formulae (full description is given in the paper regarding famotidine; Mirceski et al. 2005) of CHE mechanism have been introduced into the software MATHCAD (1998) to simulate the voltammetric response and to study the properties of the CHE. The results confirm that the catalytic hydrogen evolution in the presence of CLT occurs.

The analysis of the influence of frequency on the recorded peak current and potential provides almost enough information to differentiate assumed probable mechanism of reduction. Considering the net peak current $I_{\mathrm{p}}$ which increases with the frequency $f$ (curve 1 in Fig. 2), we confirmed that the presented results are in accordance with the irreversible surface processes (Lovric 2002). The linear dependence would be expected for simple surface process. In our case, an increase of the frequency causes on one hand an increase in the peak current, what is typical for most of the reversible and quasireversible mechanisms in SWV, and on the other hand, shows influence of the catalytic parameter on the voltammetric response. Therefore, the ensuing dependence is a compromise between these two effects. When increasing the frequency, the peak potential shifts linearly towards more negative potentials with logarithm of the frequency. The slope of the line is $-75 \mathrm{mV}$, and the theoretical value
(Mirceski et al. 2007) equals $-2.303(R T / n \alpha F)$, thus the electron transfer coefficient is $\alpha=0.79$.

It has been established by numerical simulations of the voltammetric response of CHE mechanism that the most typical feature of the catalytic mechanism is the linear dependence between $\log \left(\Psi_{\mathrm{p}}\right)$ versus $\log \left(\kappa_{\text {cat }}\right)$ (see Fig. 3 in the work describing famotidine; Mirceski et al. 2005), where the catalytic parameter is defined as $\kappa_{\text {cat }}=k_{\mathrm{p}} / f$. In the experimental analysis, this type of dependence can be obtained by plotting $\log \left(I_{\mathrm{p}} / f\right)$ versus $\log (1 / f)$. Such dependence measured in the presence of CLT is depicted by curve 2 in Fig. 2. Plotting the dependence dimensionless peak current $\Psi_{\mathrm{p}}$ versus $\log f$ for theoretically simulated catalytic hydrogen evolution mechanism, a descending curve can be observed (curve 1 in Fig. 3). This corresponds to the experimental results received for CLT (curve 2 in Fig. 3). It confirms clearly the mechanism of the reduction of the pesticide which is the catalytic hydrogen evolution mechanism.

\section{Analytical Characteristics of Clothianidin}

The analytical response for the voltammetric determination of CLT was studied using the experimental conditions described in the previous section. A series of voltammograms recorded for increasing concentration of the pesticide is shown in Fig. 4a. It indicates proportionality between the catalytic hydrogen evolution peak height and the concentration of the analyzed pesticide in the voltammetric cell. The peak current is linearly related to CLT concentration over the range $9 \times 10^{-9}-1 \times 10^{-7}$ and $1 \times$ $10^{-7}-4 \times 10^{-6} \mathrm{~mol} \mathrm{~L}^{-1}$ (Fig. $4 \mathrm{~b}$ shows the first concentration interval; the second is depicted only in part for appropriate overview of the concentration ranges). The

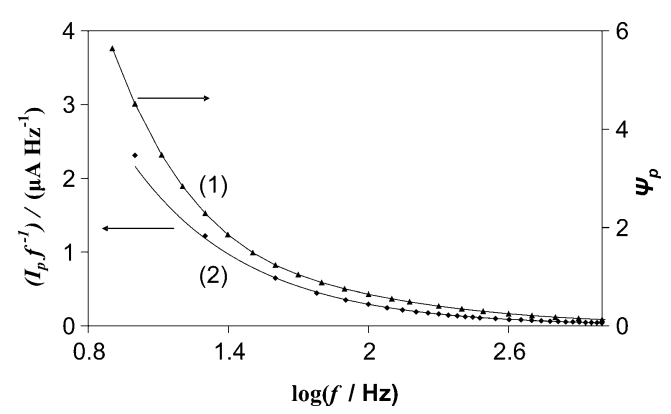

Fig. 3 Theoretical results (curve 1, right axis). Dependence of the dimensionless SW peak current on the logarithm of the frequency of the potential modulation. The conditions of the simulations were: $\mathrm{pH}=1$, $\log \left(k_{\mathrm{f}}\right)=3$, and $\log \left(k_{\mathrm{b}}\right)=0$. Simulation set was done for standard rate constant $k_{\mathrm{s}}=0.1 \mathrm{~cm} \mathrm{~s}^{-1}$, number of electrons $n=1$, electron transfer coefficient $\alpha=0.5$, diffusion coefficient $D=5 \times 10^{-6} \mathrm{~cm}^{2} \mathrm{~s}^{-1}$. The conditions of the potential modulation were amplitude $E_{\mathrm{sw}}=50 \mathrm{mV}$ and step potential $\Delta E=5 \mathrm{mV}$. Experimental results (curve 2, left axis). The influence of $\log (f)$ on the ratio $I / f$. The conditions of the experiments were the same as in Fig. 2 

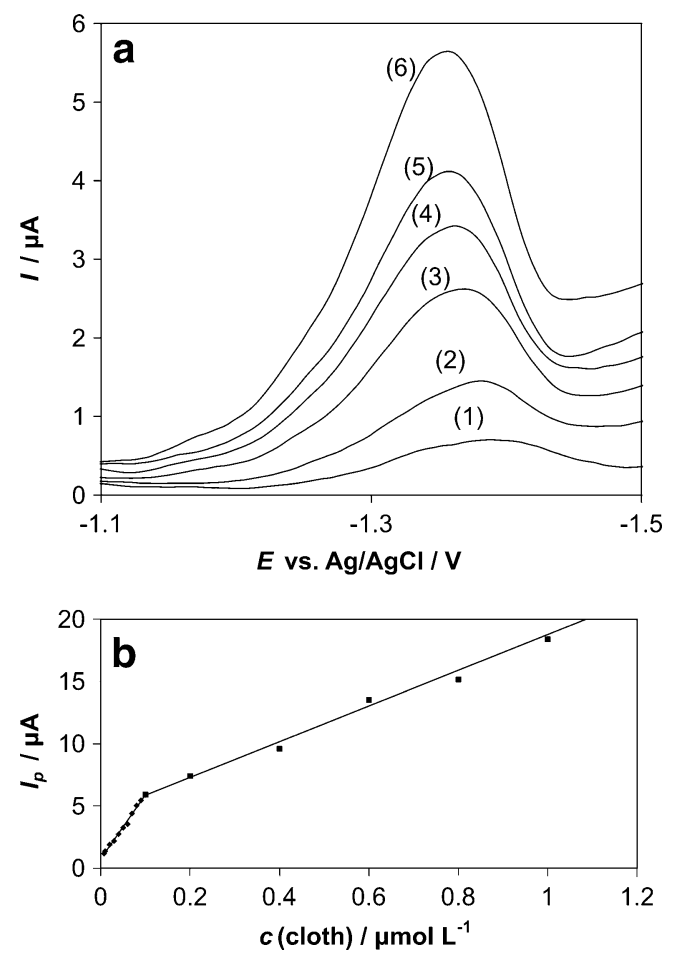

Fig. 4 a SW voltammograms of CLT recorded in citrate buffer solution at $\mathrm{pH} 2.2 . c\left(\mathrm{CLT} \times 10^{-7}\right): 10.08,20.2,30.4,40.6,50.8$, and $61 \mathrm{~mol} \mathrm{~L}^{-1}$. The conditions of the potential modulation were frequency $f=200 \mathrm{~Hz}$, amplitude $E_{\mathrm{sw}}=100 \mathrm{mV}$, and step potential $\Delta E=7 \mathrm{mV}$; accumulation for $7 \mathrm{~s}$ at $-0.35 \mathrm{~V}$. b Corresponding calibration lines

adsorption process can affect the dependence of the peak current on concentration even at low concentrations of the adsorbed compound. Formation of a first layer is characterized with lower concentration interval. This can be explained by more favorable electron transfer in the closest vicinity of the electrode. Formation of the subsequent layers corresponding to the second concentration range is characterized by reduced feasibility of an electron to cross the electrode/citrate buffer $\mathrm{pH} 2.2$ interface (the distance from the electrode surface increases). Further divergence from linearity can be explained through saturation of these layers. The mathematical relation between analytical signal $(\mu \mathrm{A})$ and concentration of the CLT $\left(\mu \mathrm{mol} \mathrm{L}^{-1}\right.$ in both ranges) was $I=(51.7 \pm 1.5) C+(0.73 \pm 0.04)$ and $I=(14.4 \pm 0.1)$ $C+(4.4 \pm 0.1)$ (for a confidence limit of $95 \%$ ), respectively. The linear responses evaluated by the correlation coefficient and average relative standard deviation were $0.994,4.6 \%$ (range 1) and $0.998,2.2 \%$ (range 2), respectively. The lowest detectable concentration (LOD) and the lowest quantitative concentration (LOQ) of the pesticide $\left(2.6 \times 10^{-9}, 8.6 \times 10^{-9}\right.$ and $2.1 \times 10^{-8}$, and $7.1 \times$ $10^{-8} \mathrm{~mol} \mathrm{~L}^{-1}$, respectively) were estimated based on the following equations: $\mathrm{LOD}=3 \mathrm{~s} / \mathrm{m}$ and $\mathrm{LOQ}=10 \mathrm{~s} / \mathrm{m}$. Abbreviation $s$ represents the standard deviation of the peak current (six runs) and $m$ stands for the slope of the
Table 1 Accuracy and precision of CLT determination with the proposed method

\begin{tabular}{llll}
\hline Added $\left[\mu \mathrm{mol} \mathrm{L}{ }^{-1}\right]$ & $\begin{array}{l}\text { Found } \\
{[\mu \mathrm{mol} \mathrm{L}]^{\mathrm{a}}}\end{array}$ & $\begin{array}{l}\text { Precision } \\
\text { RSD }[\%]\end{array}$ & $\begin{array}{l}\text { Accuracy } \\
{[\%]^{\mathrm{b}}}\end{array}$ \\
\hline $\begin{array}{l}\text { Supporting electrolyte } \\
(8 \pm 1) \times 10^{-3}\end{array}$ & 6.45 & 105.0 \\
0.008 & $(2.8 \pm 0.4) \times 10^{-2}$ & 1.72 & 93.5 \\
0.03 & $(7.1 \pm 0.5) \times 10^{-2}$ & 6.36 & 101.1 \\
0.07 & $0.100 \pm 0.007$ & 1.69 & 100.1 \\
0.10 & $0.803 \pm 0.022$ & 2.80 & 100.3 \\
0.80 & $2.08 \pm 0.04$ & 1.58 & 104.2 \\
2.00 & & & \\
Spiked tap water & $(2.01 \pm 0.05) \times 10^{-2}$ & 2.5 & 100.5 \\
0.02 & $0.202 \pm 0.003$ & 1.5 & 101.1 \\
0.20 & & & \\
Spiked apple juice & $0.21 \pm 0.08$ & 3.7 & 104.5 \\
0.20 & & & \\
Spiked soil & $0.21 \pm 0.02$ & 9.7 & 101.6 \\
0.20 & & & \\
\hline${ }^{\mathrm{a}} t\left(S / n^{1 / 2}\right), p=95 \%$ & & \\
${ }^{\mathrm{A}}$ Accuracy $=[($ Found - Added $) /$ Added $] \times 100 \%$ &
\end{tabular}

related calibration curve (dos Santos et al. 2004). The repeatability ( 1 day) of the voltammetric procedure was assessed on the basis of six repetitive measurements at a single CLT concentration. In both concentration ranges, the RSD of the peak current changed from $1.69 \%$ to $6.45 \%$ and from $1.01 \%$ to $7.48 \%$, respectively. Precision and accuracy of the method were checked by determination of CLT for different concentrations in linear ranges. The results are presented in Table 1. The validation parameters (Gumustas and Ozkan 2011) show a satisfactory performance in the presented method.

\section{Effect of Interferences}

We have examined other commonly used pesticides like demeton, cyromazine, thiophanate methyl, methidathion,

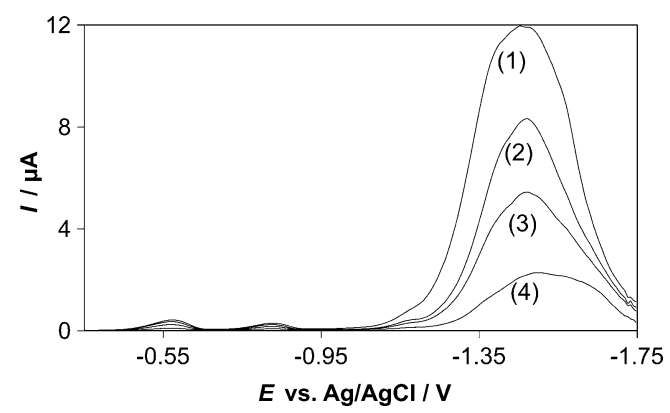

Fig. 5 SW voltammograms of CLT determination in spiked apple juice sample using standard addition method; $c$ (added CLT) $16 \times 10^{-7}, 24 \times 10^{-7}, 32 \times 10^{-7}$, and $40 \mathrm{~mol} \mathrm{~L}^{-1}$; after subtraction of the blank. Experimental conditions the same as in Fig. 4 
fenthion, acibenzolar-S-methyl, and diazinon. The presence of these compounds (in citrate buffer at $\mathrm{pH} 2.2$ ) was investigated with respect to the peak current and potential of the catalytic hydrogen evolution in the presence of CLT. The presence of diazinon always hindered the peak related to the presence of clothianidin in the solution. Methidathion, thiophanate methyl, demeton, and fenthion caused no interference of up to 20 -fold. The presence of cyromazine (concentration of up to 20-fold) caused a constant decrease of the peak current of about $15 \%$. The presence of increasing concentration of an acibenzolar- $S$-methyl caused a systematic decrease of the peak current up to $40 \%$ (20-fold).

Method Application in Tap Water, Apple Juice, and Soil Samples

The developed procedure has been applied for the determination of the clothianidin in spiked samples of tap water, apple juice, and soil. Their pretreatment was described in the "Preparation of Solutions and Sample Treatment" section. No interference was noticed from tap water or apple juice. The linear concentration range for tap water sample was found to be the same as in supporting electrolyte. Analogous range for apple juice sample was found to be $1 \times 10^{-7}$ to $4 \times 10^{-6} \mathrm{~mol} \mathrm{~L}^{-1}$. Correlation coefficient and relative standard deviation for apple juice were 0.995 and $4.9 \%$.

Square-wave voltammograms of standard addition method employed in determination of CLT in spiked apple juice are depicted in Fig. 5. The same method was used for determination of CLT in spiked tap water. The concentration of standard additions was from the linear range of the pesticide recorded peak current. The results given in Table 1 show satisfactory results of clothianidin determination in investigated tap water and apple juice samples.

The sample of soil influenced the recorded peak current of CLT as some interferences gave a signal close to the catalytic hydrogen evolution in the presence of clothianidin. In spite of the interferences linear concentration range was found to be $2 \times 10^{-7}$ to $1 \times 10^{-6} \mathrm{~mol} \mathrm{~L}^{-1}$. Correlation coefficient and relative standard deviation were 0.989 and $6.5 \%$, respectively. As shown in Table 1, it was still possible to determine the analyzed pesticide with satisfactory results. Recovery tests were made in analyte fortified samples using standard addition method. Hence, the method is sufficiently accurate and precise to be applied to the CLT determination in investigated real samples.

\section{Conclusions}

Clothianidin, as the antagonist against nicotinic acetylcholine receptor, is one of the most effective insecticides for control of broad spectrum of pests. The electrochemical study on the behavior of CLT was extended. This pesticide is not only electrochemically active at the hanging mercury drop electrode on account of nitro group reduction (Guziejewski et al. 2011), but it also exhibits effective catalytic activity toward hydrogen evolution reaction, which is the basis for its quantitative voltammetric determination performed in this work. Comparing the analytical utility and performances of the both clothianidin determination methods, it is seen that the presented one broadens the concentration range from $9 \times 10^{-9}$ to $4 \times 10^{-6} \mathrm{~mol} \mathrm{~L}^{-1}$. The other necessary validation parameters for electrochemical studies (accuracy and precision) are at the same level. The most important advantage of the depicted results arises from the fact that common reducible substances present in the environmental or biological samples exhibit electrochemical activity at much more positive potentials than the response due hydrogen evolution reaction. Hence, no significant interferences have been observed when the voltammetric method was applied to diluted apple juice or spiked soil.

The electrochemical behavior of CLT at HMDE provides a useful tool for detection and determination of the pesticide in real samples. It is a unique possibility of choosing the analytical signal, depending on environmental sample. This study shows that the CLT can be determined using the voltammetric technique in tap water, apple juice, and soil samples. The determination procedure of the pesticide in real samples requires simple steps of sample preparation. With this study, we have shown that there is a great possibility of monitoring this particular pesticide, making the method useful for environmental and food control against CLT. It could also be adopted for quality control laboratory studies as well. Moreover, the proposed voltammetric method can serve as a good alternative to HPLC, GC, LC-MS, and other pesticide analysis techniques.

Acknowledgements This work was supported by Grant No. 505/708 from the University of Lodz, Poland.

Open Access This article is distributed under the terms of the Creative Commons Attribution Noncommercial License which permits any noncommercial use, distribution, and reproduction in any medium, provided the original author(s) and source are credited.

\section{References}

Banica FG, Ion A (2000) In: Meyers RA (ed) Encyclopedia of Analytical Chemistry. Wiley, Chichester, pp 11115-11144

dos Santos LBO, Abate G, Masini JS (2004) Talanta 62:667

Gumustas M, Ozkan SA (2011) Open Anal Chem J 5:1

Guziejewski D, Skrzypek S, Łuczak A, Ciesielski W (2011) Collect Czechoslov Chem Commun 76:131

Jeschke P, Nauen R (2008) Pest Manag Sci 64:1084

Jeschke P, Nauen R, Schindler M, Elbert A (2011) J Agric Food Chem 59:2897 
Lovric M (2002) In: Scholz F (ed) Square-wave voltammetry in electroanalytical methods: guide to experiments and applications. Springer, Berlin, pp 111-133

MATHCAD (1998) MathSoft Inc., Cambridge, MA

Mirceski V, Lovric M (2001) J Electroanal Chem 497:114

Mirceski V, Skrzypek S, Ciesielski W, Sokołowski A (2005) J Electroanal Chem 585:97

Mirceski V, Komorsky-Lovric S, Lovric M (2007) In: Square-wave voltammetry: theory and applications, F. Scholz (ed). Springer, Heidelberg

Mirceski V, Guziejewski D, Skrzypek S, Ciesielski W (2010) Croat Chem Acta 83:121

Pacheco WF, Doyle A, Duarte DRA, Ferraz CS, Farias PAM, Queiroz Aucelio R (2010) Food Anal Methods 3:205
Papp Z, Svancara I, Guzsvany V et al (2009) In: Vytras K, Kalcher K, Svancara I (eds) Sensing in Electroanalysis, vol 4. University of Pardubice, Pardubice, pp 47-58

Schmuck R, Keppler J (2003) Pflanzenschutz-Nachr Bayer 56:26

Skrzypek S (2010) Electroanalysis 22:2339

Skrzypek S, Nosal-Wiercinska A, Ciesielski W (2009) Collect Czechoslov Chem Commun 74:1455

Smyth MR, Vos JG (eds) (1992) Analytical Voltammetry, vol 27. Elsevier, Amsterdam-London-New York-Tokyo, pp 138-140

Sreedhar NY, Sankara Nayak M, Shashi Kumar KN, Srinivasa Prasad K, Reddy Prasad P (2010) Environ Monit Asses 170:59

Thriveni T, Rajesh Kumar J, Lee J-Y, Sreedhar NY (2009) Food Anal Methods 2:66

Uneme H (2011) J Agric Food Chem 59:2932 